que l'homme sur la terre. Si haut qu'on remonte dans le passé, on y découvre leur trace. On les voit se manifester en tout siècle et en tout pays chez les peuples les plus différents de génie et de mcurs, les plus séparés par des distances de temps et de lieux...

C'est qu'en effet, comme le dit fort bien Rivarol, les proverbes sont les fruits de l'expérience des peuples, et comme le bon sens de tous les siècles réduit en formule...

No hacen falta más citas. Lo que me interesa mostrar es cierto aire de familia, muy de la época, y frecuente sobre todo en libros franceses. Quizá el punto de arranque de estas ideas esté en el siglo xvin (Vico, Herder), pero es natural sospechar que Hernández las conociera sólo a través de textos como los citados.

El relativamente detallado prólogo de la Vuelta nos ofrece por último, y de manera indirecta, su propia fecha de composición (no la fecha de composición del poema mismo, el cual, según sabemos, fue elaborado por Hernández con más tiempo y tranquilidad que la $I d a$ ). En efecto, la introducción de Vicente Fidel López a Las neurosis... de Ramos Mejía (cf. ed. cit., p. 88), escrito citado por Hernández, lleva la fecha 24 de octubre de 1878 . Como era previsible, el prólogo de la Vuelta, elaborado después de la terminación del poema, es poco anterior a la impresión de la obra.

Emilio Carilla

\title{
LA ADJETIVACIÓN MODERNISTA EN RUBÉN DARÍO
}

En otra ocasión hemos señalado la importancia que tiene el adjetivo en la estética modernista ${ }^{\mathfrak{x}}$. Examinando ahora el empleo del adjetivo en la obra lírica del mayor poeta del modernismo, trataremos de poner de relieve la esencia de su modernidad.

La poesía de Rubén Darío anterior a 1887 es, en su mayor parte, de léxico netamente tradicional, por lo cual no la tomaremos en cuenta aquí. Limitaremos nuestro análisis a las poesías contenidas en los seis tomos que van de $A z u l$ a Canto a la Argentina y otros poemas, y estudiaremos sobre todo los adjetivos que expresan percepción sensorial.

En su empleo del adjetivo, como en los demás aspectos de su creación, Rubén Darío es poeta de genio sintético. No inventa adjetivos, y raras veces usa neologismos y galicismos ${ }^{2}$. Por lo general, su adjetivación es tradicional y castiza. Sin embargo, renueva el adjetivo mediante una serie de procedimientos que a continuación expondremos.

\section{ReNOVACión DEL SENTIDO TRADICIONAL}

1) El adjetivo, clave de una metáfora.-Aunque el sustantivo suele llevar el peso de la metáfora, el adjetivo es el que realmente la explica.

${ }^{1}$ E. García-Grón, “ $\alpha \mathrm{La}$ azul sonrisa”. Disquisición sobre la adjetivación modernista", RevIb, 20 (1955), pp. 98-99.

${ }^{2}$ Sus escasos neologismos suelen ser más bien verbos y sustantivos como panamericanizar, nemrodizar, canallocracia, mediocracia, bulevares, etc., y aparecen sobre todo en su prosa. 
Así, en el verso "el vasto altar en donde triunfa la azul sonrisa" (La espiga, PP, 24o $)^{3}$, la metáfora -asociación metagógica de un adjetivo descriptivo con un sustantivo metafórico- está en sonrisa, pero el adjetivo azul nos hace ver que se trata del cielo. En el poema $A$ Rémy de Gourmont (ECE, 353) encontramos una metáfora análoga, aunque algo más vaga por lo abstracto del sustantivo y la ambigüedad del adjetivo (¿cielo o mar?):

Aquí estaría Simona

bajo un toronjero en flor,

viendo las velas latinas

en la azulada visión.

En este género de metáforas aparecen con mayor frecuencia los adjetivos que denotan sensación colorista; no faltan, sin embargo, las metáforas hechas a base de adjetivos acústicos o fónicos, como ésta de Cosas del Cid (PP, 233): "Las ermitas lanzaban en el aire sonoro / su melodiosa lluvia de tórtolas de oro". En Canción (a la manera de Valtierra) (PP, 237) encontramos una sinestesia acústica de indudable estirpe gongorina, en la cual el adjetivo describe el murmullo del agua en la fuente:

$$
\begin{aligned}
& \text { Y mientras la hermosa juega } \\
& \text { con el sonoro diamante, } \\
& \text { más encendido que amante } \\
& \text { el fogoso amante llega... }
\end{aligned}
$$

En Prosas profanas y en Cantos de vida y esperanza se encuentran a cada paso fonismos como "sonora rosa métrica", "sonoro marfil", "sonora perla", "sol sonoro", y aún más frecuentemente las sinestesias opuestas, en que una imagen visual se aplica a los sonidos (fotismo): "verso azul", "purpúreo y ardiente vibrar de tu palabra", "sonetos áureos", "arpegios áureos", "verso de oro", "risas blancas", "risa de plata".

En la metáfora modernista entra también en juego el simbolismo de los colores. Sabido es que, a partir del romanticismo, el color suele traspasar en la poesía su función puramente pictórica o sensorial y adquirir mayor trascendencia sugestiva mediante procedimientos relacionados con la pintura y la música del impresionismo y del simbolismo franceses ${ }^{4}$. El matiz simbólico e impresionista que el adjetivo cromático adopta en la poesía finisecular concuerda con el concepto de la poesía como exteriorización de una experiencia interna, casi mística - "un phénomène psychique $\mathrm{X}$, qui ne se produit que dans les esprits bons conducteurs: si l'on préfère, une visitation" ${ }^{5}$. La poesía trata de expresar la intimidad del poeta, pero no puede emplear los métodos directos de la lógica para co-

${ }^{3}$ Citamos por la siguiente edición: Rubén Darío, Poesía, ed. E. Mejía Sánchez, México, 1952; empleamos estas abreviaturas: A: Azul...; PP: Prosas profanas y otros poemas; CVE: Cantos de vida y esperanza; ECE: El canto errante; PO: Poema del otoño y otros poemas; CA: Canto a la Argentina y otros poemas.

* Sobre la función extra-sensorial del color en la poesía véanse estos excelentes análisis: E. K. MApes, L'influence française dans l'ouvre de Rubén Dario, Paris, 1925, pp. 75-85; Y. Pino SaAvedra, La poesia de Julio Herrera y Reissig, Santiago de Chile, 1932, pp. 76-83; María Hortensia LaCAU, El mundo poético de Conrado Nalé-Roxlo, Buenos Aires, 1954, pp. 231-261.

5 M. Raymond, De Baudelaire au surréalisme, Paris, 1947, p. 57. 
municar lo que es trance inefable. Nuestra esencia, lo íntimamente nuestro, es la sensación; pero la sensación, a diferencia de la idea, no puede comunicarse. Un concepto lógico es definible, pero la sensación de verde, por ejemplo, sólo puede experimentarse; por lo tanto, la poesía que tiende a expresar sensaciones deja de comunicar y se convierte en una manera de sugerir. Esto exige del poeta el dominio de un sistema de símbolos que sugieran al lector algo parecido a la intuición creadora inicial ${ }^{6}$. De ahí el carácter personalisimo de la poesía modernista. "El modernismo - dice Valle-Inclán- consiste en que da sensaciones, que es lo verdaderamente personal, mientras las otras literaturas sólo daban ideas, cosas propias del ambiente" 7 . En resumen: el colorido, cuando no es mera decoración o puro goce sensual, es la expresión sintética de estados anímicos.

En El reino interior (PP, 230), Darío puede dar a lo blanco la connotación tradicional de pureza, castidad, etc.:

Por el lado derecho del camino adelanta, el paso leve, una adorable teoria virginal. Siete blancas doncellas, semejantes a siete blancas rosas de gracia y de armonia que el alba constelara de perlas y diamantes;

pero también, como Melville, puede darle una connotación de pavor, al asociar una sensibilidad pura e inmaculada con lo satánico- antítesis predilecta de la escuela decadentista de Baudelaire, Huysmans y D'Annunzio-; así en el Elogio del Ilmo. Señor Obispo de Córdoba... (ECE, 322): "un báculo que era como un tallo de lirios, / una vida en cilicios de adorables martirios, / un blanco horror de Belcebú". En cambio, en la descripción de los estragos que causó el terremoto italiano de 1908 (Santa Elena de Montenegro, PO, 384 ) el horror se tiñe del valor afectivo de la tragedia por medio del adjetivo negro:

Región que el espanto prefiere

y en donde la Muerte más hiere...

¡Ay! ¡Miserere!... ¡Miserere!

¡Mas oíd un celeste allegro!

Es que pasa en el horror negro

Santa Elena de Montenegro.

El rojo suele ser símbolo de la violencia, la destrucción o la concupiscencia, sin duda por asociación con el color de la sangre, y refleja siempre un contenido emocional, un estado de ánimo del poeta:

Sangre de los martirios. El salterio.

Hogueras, leones, palmas vencedoras;

los heraldos rojos con que del misterio

vienen precedidas las grandes auroras.

Sangre que vierte el cazador. El cuerno.

Furias escarlatas y rojos destinos

"Véase T. S. ELtot, "The three voices of poetry", The Atlantic Monthly, April 1954 , p. $4^{2}$.

"Modernismo", en Ilustración Española y Americana, 22 de febrero de 1902, p. 114 . Cf. también lo que dice MAx Aub, La poesia española contemporánea, México, 1954, p. 73 . 
forjan en las fraguas del oscuro infierno

las fatales armas de los asesinos.

$$
\text { (Canto de la sangre, PP, 223) }
$$

Al lado izquierdo del camino y paralela-

mente, siete mancebos...

vienen también. Sus labios sensuales y encendidos, de efebos criminales, son cual rosas sangrientas... - Príncipes, estrechadme con vuestros brazos rojos!

(El reino interior, $\mathrm{PP}, 230-232$ )

2) Empleo del sentido etimológico.-Uno de los aspectos más interesantes del modernismo, y a la vez uno de sus muchos paralelos con el barroco, es el esfuerzo deliberado por enriquecer el léxico poético. Pero el modernismo no suele hacerlo con troquelaciones cultas, sino que vuelve al significado etimológico de las palabras, perdido ya en sus connotaciones modernas. Por ejemplo, el adjetivo flamante $^{8}$ no se asocia ya con la idea de 'llama'; Darío restaura justamente esa asociación original (Dezir, PP, 234):

Y al llegar la primavera,
en mi roja sangre fiera
triple llama fue encendida;
yo al flamante amor entrego
la vendimia de mi vida
bajo pámpanos de fuego.

Lo mismo cabe decir de aquilino, adjetivo con que se describe un rostro o, más comúnmente, una nariz semejante al pico del águila, y que Darío emplea en su sentido etimológico: "Hay algo que viene como una invasión aquilina / que aguarda temblando la curva del Arco Triunfal" (A Francia, ECE, 314). Tampoco es común el empleo de equino como equivalente del genitivo 'de caballos': "y huya el tropel equino por la montaña vasta" (Responso, PP, 223). Y argentino suele designar sólo un sonido (especialmente el de la voz humana), mientras que Darío lo emplea para referirse al metal mismo: "o el que ha detenido su carroza argentina" (Sonatina, PP, 188); "y ve pasar en su torre argentina / a un rey de Oriente sobre un dromedario" (Pórtico, PP, 212)

3) Aprovechamiento del sentido ambivalente.-En las frases adjetivales, especialmente en las de sentido metafórico, la construcción preposicional acentúa la metáfora y a veces la crea, mediante la combinación del sentido concreto con el abstracto. Por ejemplo, en el soneto J. J. Palma, "ella, al cantor ofrece la septicorde lira, / o, rítmica y sonora, la flauta de cristal" (A, 181), de cristal acentúa la metáfora mucho más que pudiera hacerlo cristalino, puesto que explícitamente describe la hechura del instrumento y a la vez sugiere su fino sonido. De modo semejante, en la metáfora "que de sangrientas rosas el fresco abril te adorne / y de cla-

8 Incluido por DÁmaso Alonso, La lengua poética de Góngora, Madrid, 1935, p. $\breve{55}$, entre los cultismos de la Soledad primera, y perteneciente al vocabulario de los poetas latinizantes de fines del siglo xIv a principios del xvi.

"En "... la América ingenua que tiene sangre indígena" ( $A$ Roosevelt, CVE, 260), ¿no tendrá el adjetivo ingenuo el sentido etimológico de 'nacido libre'? 
veles de rubi" (Responso, PP, 222), no sólo se evoca el color encarnado, sino que se reviste a los claveles de todas las cualidades de la piedra preciosa.

4) A provechamiento del sentido plurivalente.-EI adjetivo plurivalente es aquel que suscita múltiples evocaciones a la vez. Un adjetivo como albo se puede emplear en lugar de blanco por un sinfín de razones estilísticas: porque es palabra desusada, por su sonido, porque presta eleva. ción al estilo, etc.; pero cuando Darío describe la blancura con el adjetivo eucaristico (Pórtico, PP, 214), la evocación es mucho más compleja:

$$
\begin{aligned}
& \text { ante su sacra y grandiosa escultura } \\
& \text { hay una lámpara en albo Carrara } \\
& \text { de una eucaristica y casta blancura. }
\end{aligned}
$$

La blancura que aquí se evoca es la de la Hostia consagrada ("pan eucarístico"), y por lo tanto el adjetivo suscita multitud de asociaciones: devoción, emoción religiosa, actitud hierática y litúrgica ante el objeto que se describe, el sacrificio de la misa, las blancas vestiduras del sacerdote y de los acólitos, los paños del altar, etc. El adjetivo fresco, además de aludir al frescor, denota lo nuevo, reciente, robusto y lozano en "cual la más fresca y gentil de las ninfas" (Pórtico, PP, 211). Múltiples son también las asociaciones del epíteto encendida (calor, color, irritación, inflamación, etc.) en Invernal (A, 171):

\author{
El Invierno es galeoto, \\ porque en las noches frías \\ Paolo besa a Francesca \\ en la boca encendida.
}

$\mathrm{Y}$ al apostrofar Darío a Verlaine: "Padre y maestro mágico, liróforo celeste..." (Responso, PP, 222), alude con el adjetivo mágico al satanismo de Verlaine (Crimen Amoris) y dice a la vez que es como el mago del zoroastrismo, el sumo sacerdote de la poesía moderna, el hechicero o astrólogo máximo de la poesía: todo esto además del sentido figurado de 'maravilloso, estupendo', etc. Pero la complejidad de asociaciones no se puede ver bien sino en el conjunto de un poema. Hay que leer, por ejemplo, el soneto Ite, missa est (PP, 202), donde no sólo cada adjetivo, sino el léxico todo va cargado de evocaciones plurivalentes.

\title{
II. InNOVACIONES ADJETIVAlES
}

1) Neologismos.-Al tratar del léxico de un poeta, es siempre dificilísimo establecer si él ha sido el primero en emplear tal o cual palabra. Sin una investigación minuciosa de infinidad de textos anteriores, sería imposible determinar hasta dónde es innovador Rubén Darío. Limitándonos a los estudios ya hechos por críticos y lexicógrafos, notamos que en realidad son escasos los neologismos darianos. El poeta suele emplear sustantivos raros, poéticos o técnicos, pero sus adjetivos son, por lo general, netamente castizos. Si algo nos sorprende es la libertad poética -por no decir licencia- con que "casa por primera vez un adjetivo con un sustantivo", como dijo Maeztu acerca de Valle-Inclán. Venusino se refiere en general a Venusa, cuna de Horacio; pero Darío lo refiere a Venus: 
"Su ave es la venusina, la tímida paloma" (Catulle Mendès, A, 180); "dos nevadas palomas venusinas" (Friso, PP, 224). Alguna vez el casamiento resulta engañoso, como cuando el poeta habla de la "firme tizona, broncineo olifante" Pórtico, PP, 215), pues olifante es 'cuerno de marfil' 10.

En general, los neologismos usados o creados por Darío han tenido fortuna, y sólo el purista intransigente les opondrá reparos. Han pasado a la lengua general no pocas voces calificadas de neológicas por Bello, Baralt, Cuervo, Toro y Gisbert y otros lexicógrafos: alucinante, apelotonado, broncineo, carnavalesco, embriagante, espectral ${ }^{11}$, fálico, florecido (por florido), jocundo, luciferino, macabro, matinal, pasional, volteriano. Otras aún se resisten: "Que el Mortui estis del candente Pablo / les forjaba corazas arcangélicas" (La cartuja, CA, 416); "En el erecto término coloco una corona" (Propósito primaveral, CVE, 302); "Sobre su altar de oro se levanta la Dea / -tal en su aspecto icónico la virgen bizantina" (La Dea, PP, 221); "O con amor hindú que alza sus llamas / en la visión suprema de los mitos" (Divagación, PP, 187); "politona y triunfante, la seguidilla..." (Elogio de la seguidilla, PP, 216$)^{12}$. Unos cuantos neologismos, obviamente útiles y formados de acuerdo con las más estrictas advertencias de Andrés Bello, son derivaciones de patronímicos que aún no registran los diccionarios: hermosillesco, jupiterino, verleniano, wagneriano. Lo mismo puede decirse de éstos que incluye Toro y Gisbert en su breve examen del vocabulario de Rubén Darío (op. cit., p. 64): extrahumano, florestal, himnico, septicorde, talismánico, tritónico.

2) Galicismos.-El "galicismo de la mente" a que alude Valera en la célebre carta-prólogo a $A z u l \ldots$ no pasa de ser eso, y fuerza es admitir que Valera tenía toda la razón cuando decía que el lenguaje de Rubén Darío es en el fondo "español legítimo y de buena ley". En la adjetivación, los galicismos llegan apenas a una media docena, y son casi todos "de imprescindible necesidad y más o menos admitidos ya por todo el mundo": "Parlanchína, la dueña dice cosas banales" (Sonatina, PP, 188); "Y las manos liliales agita, como infanta..." (El reino interior, PP, 230); "Entonces el buen Dios, allá en su trono..." (Ananké, A, 175); "... un vulgo errante, municipal y espeso" (Soneto autumnal. .., CVE, 298)13; "Fanfarrias macabras, responsos corales" (Canto de la sangre, PP, 224) ${ }^{14}$; "Un coro de poetas y pintores / cuenta historias picantes" (Diva-

10 Miguel de Toro y Gisbert, Los nuevos derroteros del idioma, París, 19ı8, p. 6o, dice que broncineo es "neologismo", pero aparece ya en Cervantes; el neologismo, aquí, es olifante.

11 El Dice. Acad. acepta espectral sólo con relación al espectro de la física, pero no en el sentido en que Darío lo emplea, y que se ha generalizado muchísimo: "...pase gigante sombra extraña, / sombra de un Sátiro espectral" (Responso, PP, 2.23).

12 Arturo Marasso, en su ed. de la Antología poética de Rubén Darío, Buenos Aires, $195^{2}$, p. $4^{18}$, dice que el neologismo politono fue "creado por la casualidad" de haberse roto la curva de la $f$ en la ed. de 1896 de Prosas profanas; según él, Darío escribió "polifona y triunfante..." (politono falta en el diccionario).

${ }_{13} \mathrm{E}$ l espeso de este último ejemplo puede ser galicismo (un homme épais, ignorance épaisse), pero también simple americanismo: el Dice. Acad. lo registra (6 $6^{\mathrm{a}}$ acepción) como argentinismo y venezolanismo con el sentido figurado de "pesado, impertinente, molesto".

${ }_{14}$ De macabro (usado en lugar del castizo fúnebre) dice Toro Y Grsbert, op. cit., p. 58 , que "está ya también muy agarrado, a pesar de su fealdad. Hay que tener la afición de los españoles hacia lo extranjero para aceptar una palabra de consonancia 
gación, $\mathrm{PP}, 186)^{15}$. El adjetivo funambulesco, en Canción de carnaval (PP, 194), más que "neologismo" - como lo llama Toro y Gisbert- es galicismo; así lo demuestran los dos versos de las Odes funambulesques de Banville que Darío pone a manera de epígrafe del poema:

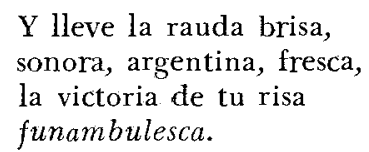

3) Restauraciones adjetivales. - Si Darío no inventa neologismos ni abusa de los galicismos, en cambio es frecuente en él, como en tantos modernistas, la restauración de viejas palabras. Muchos de sus adjetivos son perfectamente castizos, pero de poco uso en el habla actual: "La andaluza hechicera, paloma arisca" (Elogio de la seguidilla, PP, ${ }_{116}$ ); "ella está toda bermeja / y tiene los ojos bajos" (Danzas gymnesianas, CA, $43^{8}$ ); "El ilustre cisne... / . . boga sobre el terso lago especular" (Flirt, ECE, 358); "cuando el himno jocundo / del despertar de Oriente..." (Ananké, A, 174); "Garrido infante, de Eros por hermoso / émulo y par..." (Friso, PP, 225). En "ni pájaro gentil que no me escuche, / ni garrido cantor que no me llame" (Ananké, A, 175), el adjetivo gentil podría ser galicismo, pero su proximidad a garrido nos hace pensar que procede más bien de la literatura castellana antigua.

4) Adjetivos puestos de moda por Dario.-Varios adjetivos, a pesar de ser tradicionales, pueden considerarse modernistas por el uso constante que de ellos hizo Darío. Él los puso de moda, como puso de moda el cisne y el color azul. Entre ellos mencionaremos divino, lírico, mágico, misterioso, sonoro, cuyo insistente empleo muestra un concepto predominantemente artístico de la poesía. La frecuencia de los adjetivos y frases adjetivales que aluden a colores brillantes (blanco, rojo, azul, verde, de oro), a la luz y al calor (luminoso, ardiente), a lo espacioso (inmenso, vasto), y de epítetos como robusto, rudo, alegre, revela al poeta sensual y pone de manifiesto el aspecto decorativo y grandilocuente de su poesía anterior a Cantos de vida y esperanza.

D. C. Heath, San Francisco.

EdMundo García-Grrón

tan estrafalaria. ¿Cuándo veremos aparecer los derivados de este «nuevo enriquecimiento» de la lengua? ¿Cuándo leeremos macabreria, macabrón, etc.?"

15 Tanto Baralt como Toro y Gisbert califican de "galicismo" el empleo de picante en el sentido de 'chistoso, extraño, desvergonzado'. En todo caso, será un galicismo bastante antiguo, puesto que el diccionario de ANICETO DE PAgÉs lo documenta con citas de Larra, Alarcón, Valbuena y Scío de San Miguel. 